\title{
Effectiveness of Code-Switching in Language Classroom in India at Primary Level: A Case of L2 Teachers' Perspectives
}

\author{
Tribhuwan Kumar $^{1 *}$, Venkanna Nukapangu $^{2}$, Ahdi Hassan ${ }^{3}$ \\ ${ }^{1}$ Assistant Professor of English, College of Science and Humanities at Sulail, Prince Sattam Bin Abdulaziz University, Al Kharj, Saudi Arabia \\ ${ }^{2}$ Assistant Professor of English, College of Science and Humanities at Sulail, Prince Sattam Bin Abdulaziz University, Saudi Arabia \\ ${ }^{3}$ Researcher, Global Institute for Research Education \& Scholarship based in Amsterdam, Netherlands
}

\section{Abstract}

The current study explores the effectiveness of code-switching (CS) in language classroom, a case of second language (L2) teachers' perspectives. Code-switching (CS) refers to a usage of the two languages in conversation and it also relates to a 'language mixing. CS may occur between sentences, known as 'inter-sentential code-switching'; and it may also occur within a sentence, known as 'intra-sentential code-switching. Code-switching is a linguistic feature of multi-lingual societies, as they are gifted with more privileges to use various languages. The current study points out the perceptions of language teachers towards code-switching in the classroom in the process of teaching and the purposes of code-switching in teaching. The data for the study includes the responses of the attitudinal test questions designed on a Likert Scale of 20 teacher- respondents from the two government schools of Delhi-NCR. The outcome of the study illustrates that the predominance of code-switching in the classrooms is used to interpret complex ideas, translate questions, seek confirmation, check students understanding, also to build solidarity and code-switching is most prevalent in primary education. Hence, code-switching is a distinctive linguistic requirement in education but there is a negative towards the use of CS in the classroom.

Keywords: Bilingualism, code-switching, first language (L1), language classroom, second language (L2) learners

\section{INTRODUCTION}

English is a global language. Almost every profession requires it. Professionals' success in the workplace is heavily reliant on their English proficiency. The English language is vital in all fields, including science, technology, entertainment, and business (Ajmal \& Kumar, 2020; Benyo \& Kumar; 2020; Kumar 2020a). The current study investigates the role of bilingualism in language classes, as well as how a learner might be exposed to two or more languages at a very basic level when starting out in a new language. In the context of Indian second language (L2) acquisition and teaching, an investigation of the function of bilingualism in learning and teaching becomes justifiable. Besides the indigenous languages, English is a second language learned at institutions.

The alternation of two or more languages is on the rise among bilinguals and multi- lingual and it's a powerful feature of informal communication (Garrett, 2010, p.11). It is consciously or unconsciously witnessed in various domains. Ryan \& Giles (1982) is also with the view that school is one most important place where there is contact between speakers of different language varieties. Hakuta (1986) also supports that schools become linguistically and culturally diverse, and therefore, recommends for varied approaches to accommodate to the requirements of learners.

In code-switching, two or more languages are used in a conversation without changing topics. The studies investigate only about the code-switching between two languages, the native language and the target language. The phenomenon of bilingualism occurs when two groups of people using different languages communicate each other constantly in such long time (Shartiely, 2013).

The code-switching can be caused the new comer does not familiar with the code being used or for other reasons, such politeness, friendship, etc. The change of the language or code happens without the change of the topic. Employing code-switching in the L2 classroom makes the teacher to run the classroom activities smoothly and meaningfully to the students.

People have different attitudes towards code-switching, and it is viewed both positively and negatively. CS is an issue, which has been broadly discussed and used in linguistics. It is the topic which bears a mixed attitude towards it. Though, code-switching is an accepted in various spheres of lives, this paper studies and presents the situations that lead to code-switching; the types of code-switching in the classroom

Corresponding Author e-mail: tribhuwan.literature@gmail.com https://orcid.org/0000-0001-7259-9364

How to cite this article: Kumar T, Nukapangu V, Hassan A, (2021). Effectiveness of Code-Switching in Language Classroom in India at Primary Level: A Case of L2 Teachers' Perspectives. Pegem Journal of Education and Instruction, Vol. 11, No. 4, 2021, 379-385

Source of support: Nil

Conflict of interest: None.

DOI: $10.47750 /$ pegegog.11.04.37

Received: 12.07 .2021

Accepted: 27.09.2021 Publication: 01.10.2021 
and more importantly; the perceptions of language teachers towards code-switching in the classroom in the process of teaching lesson delivery (Kumar, 2021; Kumar, 2020 b).

\section{Research Objectives}

Following are the research objectives:

- To investigate the effectiveness code-switching in Language classroom.

- To discover the students' reasons of employing codeswitching in English class.

- To examine the perception of the language teachers about the role of bilingualism in the English language class.

\section{Research Questions}

Based on the background, the research questions are:

(i) What is the perception of the teachers towards using codeswitching in the language classroom?

(ii) What patterns of code-switching do the students employ in the English class?

(iii) What are the students' reasons of employing codeswitching in the English class?

\section{Literature Review}

Gulzar (2010) indicated that the code-switching is occurred in language classroom to focus the needs of the L2 learners. He further described the role of code-switching in bilingual classrooms used as a tool in giving instruction effectively, to do clarification, checking understanding, translation, ease of expression creating a sense of belonging socializing, linguistics competence and repetitive functions.

An English teacher prefers to use native language while translating unfamiliar words. It is considered to be easier. They also use the native language while giving instruction in the matter of classroom management, such as arranging the students' sitting while working in a group discussion, reminding the students about their unwelcomed behaviour; such as for being impolite to their friends or the teacher, asking the students not to be noisy, and so on. They employ this in the reason of saving time. The classroom can be handled more easily, and L1 itself can be a kind of strategy to draw on. The students' undesired behaviour such as being noisy, talking too loudly, disturbing other students, or walking around for cheating could be handled easily by using their own first language.

The figure above emphasizes the lexical relationship between the second and first languages, demonstrating that the second language is more powerful than the first in this regard. In terms of conceptual memory, first language is superior to second language, whereas second language is superior in terms of procedural memory.

The richness and diversities in languages have empowered people to employ various languages in their day to day communication. Goodman (2006) explains that CS occurs when modern topics, such as the world of business or politics are discussed rather than traditional issues such as narrating stories from the past. It is most prevalent in multilingual and bilingual societies and its occurrence has some repercussions on the society. Moreover, Boztepe (2003) asserts that CS is often frowned by monolinguals, and dismissed as gibberish. Boztepe (2003) defines the bilingual that "switches from one language to the other according to appropriate changes in the speech situation (interlocutors, topics, etc.), but not in an unchanged speech situation, and certainly not within a single sentence". (p.2). Dendup (2010) also argues that code-switching occurs to the learners who are not good in their language. As it is apparent from the above lines; it mostly occurs when one is at the loss of words and it questions one's fluency. This is

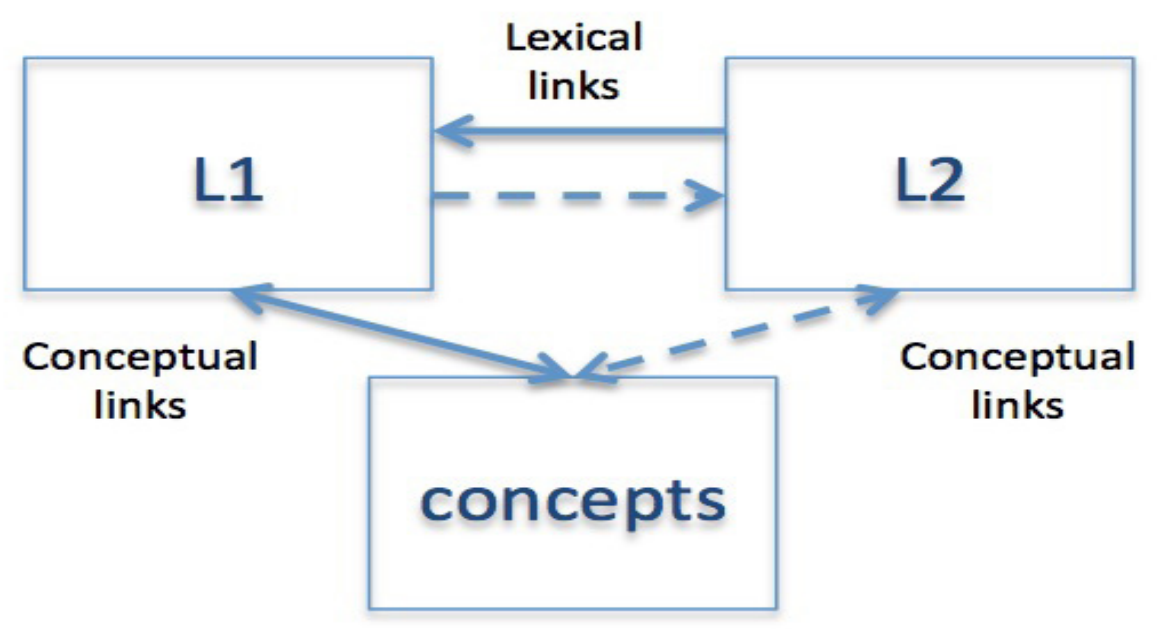

Fig.1: Lexical connection of L1 \& L2 
a serious weakness. Dendup (2010) also, however, supports the lack of technical terms or concepts incur the necessity to borrow, which in turn may act as a cause for the code switch. On the contrary, Garrett (2010) argues that the phenomenon is considered nothing more than speakers making full use of a bilingual situation, and is in no way stigmatized.

Code-mixing can also lead to the evolution of new languages. As Dendup (2010) mentioned that when codemixing is so extreme or frequent it can lead to an origin of language known as "Media Lingua halfway language" which is spoken as the usual everyday language.

In the field of education, some teachers use code-switching as one important tool to teach students and meet their diverse needs. In line with this, Hakuta (1986) brings out that "classrooms have become culturally and linguistically diverse, and we need teaching strategies that celebrate and use that diversity as a springboard to wider knowledge" (p.10). Various studies have been conducted into the use of code-switching at different levels. A study was conducted by (Shartiely, 2013) to study the various functions of code-switching between English and Swahili in a bilingual or multilingual classroom.

\section{Mother Tongue (L1) Vs Second Language/Foreign Language (L2)}

An official second language is one that is not spoken by the native speakers of a country, according to Nesamalar, Saratha, and Teh (1995). India like many countries having many regional languages in different states, and within the same region having different languages where English is spoken as a second language, not as a first. English is widely used in trade and everyday conversation and is used for a range of reasons and by a variety of people all over the world. As a result, it is an ideal choice for a second language.English is also considered the first language while turning into secondary education onwards to tertiary. Due to little exposure to the language in rural areas of nations like Libya and Tunisia (where French is considered to be the second language), English can appear to be a foreign language in these areas.

According to Willis (1996), speaking in one's mother tongue has a significant and positive impact on one's performance. Allowing the mother tongue to be used creates more opportunity for the target language to be used. In general educational psychologists and intellectuals and many researches proved that if a person is perceptive of his/her mother tongue will also be well informed of the other tongue. Also, Ovando, Collier and Combs (2003) believe that academic and literacy skills are developed in the first language and then transferred to the second. It is easier to interpret complex ideas, to translate questions, to seek confirmation, and smother to build solidarity. Nesamalar (1995) states that mother tongue is the child's parents' native language. It is quite likely that the child's mother tongue is the child's first language if it is spoken at home from an early age. The first language, on the other hand, is the one with which a person feels most at ease while interacting with others in a social setting. When the person develops his/her mother tongue, he/she is alternatively nurturing the other essential skills such as critical thinking, interpretation of complex ideas, literary skills where these skills that they take with them into formal education, vocational education and also into the professional education. According to the findings of numerous research studies, any skill or concept learned in the learner's native language does not need to be retaught when the learner switches to a second or foreign language.

There are many different languages spoken throughout India. In India, there are dozens of distinct regional languages that share many traits, such as grammatical structure and lexicon. Apart from these languages, Hindi is the most widely spoken language in India. For central administrative purposes, India has two national languages: Hindi and English. India's primary, official, and main communication language is Hindi. An associate official language is English. In addition, twentytwo regional languages have been recognized by the Indian Constitution as official languages, in addition to the national language.

The Hindi language has its origins primarily in the north of India, but it is now spoken and understood widely throughout the country's urban areas. There is more animosity toward Hindi in southern India, where people speak a variety of languages that are not closely related to Hindi, allowing English to remain a lingua franca to a greater extent. The majority of Indians can legitimately claim to be multilingual, having first acquired their mother tongue, then Hindi as their national language, and finally English as their Lingua Franca.

The English language has been present in the Indian subcontinent since the early 1600s, when the East India Company established settlements in Madras, Calcutta, and Mumbai (all formerly known as Bombay). India's historical setting is inextricably linked to modern English usage. India has had a lengthier exposure to English than any other country that speaks it as a second language, with its particular vocabulary, idioms, syntax, and rhetoric progressively penetrating all locations, habits, and culture.

English serves two unique goals in India. It promotes administrative homogeneity by bringing together persons who speak different languages. Second, it functions as a language of broader communication, including a wide range of people across a large geographic area. In some realms of influence and public spaces, it overlaps with local languages.

\section{Methodology}

This study resorted to employing both structured and unstructured attitudinal questionnaire based on a Likert 
scale scoring procedure, i.e. strongly disagree to strongly agree. The respondents were selected from two different government Secondary Schools of Delhi-NCR. There were a total of twenty (20) teacher participants. The participants varied in terms of their service in teaching. Regarding experience, Five participants belonged under the category 1-5 years, 10 (participants) under the category 6-10 years, four (4) participants under the category $11-15$ years and one (1) participant under the category 16-20 years.

A questionnaire survey designed, administered to the respondents after seeking prior permission and consent from the participants and their respective school heads which took at least a couple of weeks. Piloting was conducted in small groups to check the reliability and validity and it underwent some change based on the constructive feedback received. The respondents were from different levels of schools, as mentioned above, and also from different geographical locations, such as rural, semi-urban and urban which facilitated to have a comparative study of the data and triangulation.

The findings of this paper are based on small convenient sampling; and therefore, the outcome of this study cannot be generalised. A bigger sampling could have been undertaken for reliability. The subject of the research was restricted to a handful of teachers and a similar survey could have been administered to a group of students for better triangulation of the data. The survey was also confined to questionnaire survey responses only. This paper calls for a larger sampling and in-class observation of teaching to gather data.

\section{Data Analysis \& Findings}

The data in the table below were obtained based on the attitudinal questions as per the Likert scale scoring procedures.

The table 1 demonstrates the findings based on the total scores and the averages of the responses agreement and disagreement of the teacher- participants. A unanimous 100\% agreed with the statement "When I code-switch between English and Hindi, learners seem to understand better". This indicates the prevalence of code-switching in the classroom while teaching and the respondents are in favour of language alternation between English and L1 as a useful means to aid the comprehension of any lessons delivered, mostly to explain complex ideas in the more intelligible language. More importantly, the use of L1 in between English, mostly the inter-sentential code-switching helps build their bond of a student-teacher relationship. Poplack (2001) mentioned that "classrooms have become culturally and linguistically diverse, and we need teaching strategies that celebrate and use that diversity as a springboard to wider knowledge" (p.10).In light of this, $65 \%$ of the participants agreed with the statement, "It would be of great help for low achievers if code-switching is used" while handling with the low achievers. There is a multiplicity of learners; therefore, no single strategy is suitable for all learners. The need for code-switching arises when low achievers $\bigotimes$ need has to be addressed so that their learning and standard is at par with high achievers. This takes place when there is an interpretation of the concept and interpretation of questions.

Table1: Statistical analysis of questionnaire

\begin{tabular}{|c|c|c|c|c|c|c|c|}
\hline \multirow[b]{2}{*}{ Statement } & \multicolumn{5}{|c|}{ Response Frequency } & \multirow{2}{*}{$\begin{array}{l}\text { Response } \\
\text { Agree } \\
(\%) \\
\end{array}$} & \multirow{2}{*}{$\begin{array}{l}\text { Response } \\
\text { Disagree } \\
(\%)\end{array}$} \\
\hline & $S A$ & $A$ & $D K$ & $D$ & $S D$ & & \\
\hline $\begin{array}{l}\text { Learners' participation would increase if Code Switching is } \\
\text { allowed in the classroom. }\end{array}$ & 11 & 3 & 3 & 2 & 1 & $14(70 \%)$ & $3(15 \%)$ \\
\hline Code Switching will not support in mastering any languages. & 10 & 3 & 1 & 3 & 3 & $13(70 \%)$ & $6(25 \%)$ \\
\hline $\begin{array}{l}\text { It would be of great help for low achievers if Code Switching is } \\
\text { used. }\end{array}$ & 6 & 7 & 5 & 2 & 0 & $13(65 \%)$ & $2(10 \%)$ \\
\hline Code Switching would enable teachers to teach well. & 1 & 9 & 3 & 5 & 2 & $10(50 \%)$ & $7(35 \%)$ \\
\hline $\begin{array}{l}\text { When I use Code Switchingbetween English and } \\
\text { Hindi, children seem to comprehend better. }\end{array}$ & 6 & 14 & 0 & 0 & 0 & $20(100 \%)$ & 0 \\
\hline $\begin{array}{l}\text { Students in lower grades must be taught using Code } \\
\text { Switching techniques. }\end{array}$ & 4 & 7 & 3 & 4 & 2 & $11(55 \%)$ & $6(30 \%)$ \\
\hline Institutions should work on it and implement it. & 2 & 3 & 6 & 7 & 2 & $5(25 \%)$ & $9(45 \%)$ \\
\hline Some subjects demand Code Switching. & 2 & 15 & 2 & 1 & 0 & $17(85 \%)$ & $1(5 \%)$ \\
\hline Teachers can deliver their lesson fluently. & 0 & 11 & 3 & 4 & 2 & $11(55 \%)$ & $6(30 \%)$ \\
\hline Code Switching helps me to complete syllabus on time. & 1 & 3 & 2 & 10 & 4 & $4(20 \%)$ & $14(70)$ \\
\hline Code Switching should be allowed in both writing and speaking. & 1 & 1 & 0 & 5 & 13 & $2(10 \%)$ & $18(90)$ \\
\hline $\begin{array}{l}\text { Weaknesses in languages force a person to use different } \\
\text { languages. }\end{array}$ & 7 & 5 & 3 & 1 & 4 & $12(60 \%)$ & $5(25 \%)$ \\
\hline Code Switching is an unhealthy language. & 6 & 6 & 3 & 3 & 2 & $12(60 \%)$ & $5(25 \%)$ \\
\hline
\end{tabular}


Taha (2008) is worthy of note to discuss code-switching as a useful classroom technique to scale up the class participation.70\% of the teacher-participants agreed with the statement "students' participation would increase if code-switching is allowed for students in the classroom. $\mathbb{A}$ classroom with less or no participation can hardly achieve the learning objectives as it can kill the learners" creativity and inquisitiveness to learn. Learners would actively participate only if what is taught is intelligible to them, and to make it comprehensive, foster involvement; code-switching is important. Though Hakuta (1986, cited in Wheeler, 2010) asserts that code-switching is often frowned by monolinguals, and dismissed as "gibberish"; but Poplack (2001) emphasizes that there should not be any stigmatization related codeswitching rather it should be treated as a resource. $80 \%$ of the respondents had the perception that some subjects demand to use more than one or more languages in the delivery of their lessons. More complex the subject is the more is the mixing of languages. As science subjects have more scientific jargons, the demand for code-switching is more than the arts subjects. Conversely, the teaching of history and civics would also be desirable and automatic for the use of more local terms, as they talk about on culture, values, art, building the solidarity. 55\% of the respondents agreed that code-switching is useful in the delivery of their lessons fluently. However, interestingly, 70\% of the respondents are against the view of the code-switching in the timely completion of syllabuses. With regards to the statement, "Students in lower grades must be taught using code-switching techniques", $55 \%$ of the respondents responded positively about using code-switching with the students in the lower grade which can make the small children understand in their early ages of transition from home environment to a school setting. On the contrary, $70 \%$ of the respondents view code-switching as a threat to learning and mastering any languages and $60 \%$ of the respondents' label code-switching as unhealthy language practice. $60 \%$ of the respondents also attributed code-switching to speakers who have low command over the target language. To stress on this, Muysken (1993, cited in Singh, 2005) mentioned that when code-switching is so extreme or frequent it can lead to an origin of language known as Media Lengua "halfway language" which is spoken as the usual everyday language.

The occurrence of code-switching is the observed phenomenon and attributed with various useful functions such as fostering class participation, easing the understanding of complex ideas, building solidarity; startlingly, a majority $90 \%$ are disagreeing with the statement "code-switching should be allowed in both writing and speaking". Code-switching should not be allowed both in writing and speaking.

This states the importance and the need to use English only or Dzongkha only while delivering English lesson and similarly, use the other target languages judiciously in both spoken and written. The findings indicate the incidences of code-switching in the classroom, but there is a negative attitude towards using code-switching in the classroom.

\section{Analysis of Open-Ended Questions Survey Responses}

Do you think this type of language mixing in the classroom is good or bad? Why?

The open-ended responses have been analysed by coding the responses into two categories: positive and negative. The alphabets used as codes are (T) for teachers, $(\mathrm{P})$ for positive and $(\mathrm{N})$ for negative.

Table 2. Responses of the teachers.

\begin{tabular}{|c|c|c|}
\hline \multirow{2}{*}{$\begin{array}{l}\text { Responses } \\
\text { It does not look nice. }\end{array}$} & \multicolumn{2}{|c|}{ Code } \\
\hline & $\mathrm{T} 1$ & $\mathrm{~N}$ \\
\hline The problem in speaking and writing. & $\mathrm{T} 2$ & $\mathrm{~N}$ \\
\hline Students will fail to learn the language properly. & $\mathrm{T} 3$ & $\mathrm{~N}$ \\
\hline Good for the lower classes. & $\mathrm{T} 4$ & $\mathrm{P}$ \\
\hline Not good for instructions. & T5 & $\mathrm{N}$ \\
\hline Convenient for the lower classes. & $\mathrm{T} 6$ & $\mathrm{P}$ \\
\hline Students can't master any language. & $\mathrm{T} 7$ & $\mathrm{~N}$ \\
\hline Weaker students can understand. & $\mathrm{T} 8$ & $\mathrm{P}$ \\
\hline Affect the written language. & Т 9 & $\mathrm{~N}$ \\
\hline Will create confusion. & $\mathrm{T} 10$ & $\mathrm{~N}$ \\
\hline Good for the lower classes. & $\mathrm{T} 11$ & $\mathrm{P}$ \\
\hline Lessons taught can be understood. & $\mathrm{T} 12$ & $\mathrm{P}$ \\
\hline Discourages from learning a good language. & $\mathrm{T} 13$ & $\mathrm{~N}$ \\
\hline Students would wait for an explanation. & $\mathrm{T} 14$ & $\mathrm{~N}$ \\
\hline Not a healthy habit. & $\mathrm{T} 15$ & $\mathrm{~N}$ \\
\hline Students won't be able to talk in good language. & $\mathrm{T} 16$ & $\mathrm{~N}$ \\
\hline Not bring any improvement. & $\mathrm{T} 17$ & $\mathrm{~N}$ \\
\hline Makes concepts clear. & $\mathrm{T} 18$ & $\mathrm{P}$ \\
\hline Students will not catch up. & $\mathrm{T} 19$ & $\mathrm{~N}$ \\
\hline Will not help in mastering any one language. & T 20 & $\mathrm{~N}$ \\
\hline
\end{tabular}

The open-ended survey question presents the convergence of the finding from the closed-ended question. In other words, both closed-ended and open-ended questions show the practice and incidences of code-switching in the classroom. As per the data, $30 \%$ of the respondents had a positive attitude towards mixing different languages in the classroom while teaching. To them, though the use of code-switching has some repercussions in the learning and mastering of language in the classroom in particular and development of new and unhealthy languages, code-switching may be used in the classroom. To quote some remarkable responses of the respondents: Teacher 4 remarked, code-switching is "Good for lower classes." And similarly, Teacher 6 remarked, code-switching is 


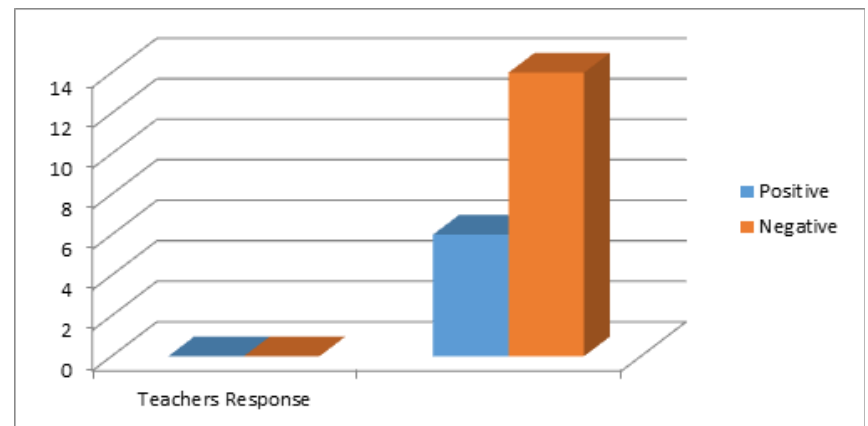

Fig.2 Teachers' response

"Convenient for lower classes." Teacher 8 also remarked that code-switching is "good for weaker students to understand."

$70 \%$ of the respondents view code-switching negatively while teaching, though it is prevalent and the need is felt usually in the lower grades for easy comprehension of lessons. Teacher 13 remarked code-switching, "Discourages from learning a good language." Teacher 16 also had a similar opinion, "Students won't be able to talk in good language." Likewise, to Teacher 15, code-switching is "Not a healthy habit" and similarly, teacher 16 expressed that "Students won't be able to talk in good language." On the whole, the findings of the open-ended response state that there is a negative attitude towards employing code-switching in language class.

The table 3 clarifies the occurrence of code-switching in a classroom situation in the process of teaching and learning. Mostly participants used code-switching 'sometimes', i.e. 80\%. It means that code-switching is not a must everyday practice. It is necessitated by a situation. $15 \%$ of the respondents use it 'most of the time' and 5\% of the respondents use it 'always' and there is none who never practices code-switching in classroom. The greater use of code-switching, most of the time and always is determined by their difficulty level of the subject taught and grades level.

\section{Conclusion}

The students employ the code-switching based on the need of finishing the task given by the teacher correctly and quickly, socializing among them, showing a group members' solidarity and having fun by telling jokes or funny things. The topic of discussion and the presence of certain people, such as the teacher and friends from other tribe, can be the reasons for the students to employ code-switching in the classrooms. The pedagogical implications of this study focus on the learners employing code-switching in English classroom. For the students, they employ code-switching as a communication approach to overcome the difficulty triggered by their limited English vocabulary. They have to switch to their own languages or they will keep silent. Teachers should pay careful attention on these because let the students to switch all the time is not
Table 3: Shows the number in each category of response type and their percentage

\begin{tabular}{lll}
\hline Responses & Number & Percentage \\
\hline Always & 3 & $5 \%$ \\
Most of the time & 3 & $15 \%$ \\
Sometimes & 14 & $80 \%$ \\
Total & 20 & $100 \%$ \\
\hline
\end{tabular}

good for their English. Since this study is very limited and only in a school, a further study with greater participants and much more time is needed to get better understanding about students' code-switching and its implication in learning English. Employing code-switching can make the students feel more confident and comfortable during the teaching and learning process but actually, it indicates that their English vocabulary is limited. As the level of learners gets higher and their competence gets better, the students have to force themselves to speak only English in the classrooms. Then, it will be wise for the teachers to motivate the students to use English mostly in the classrooms. It will ease them to face the real English communication outside the classrooms.

Code-switching is prevalent in Bhutanese classroom. The teachers use CS to explain a complex concept, to build up a student-teacher relationship for a better and conducive learning environment, seek confirmations and translate questions. The use of code-switching aided in catering the need of diverse learners. Importantly, code-switching is feasible with learners of lower grades; as their second language would be less intelligible. However, code-switching is viewed negatively, though there is an incidence of its prevalence. It is a barrier to learning the target language and mastering the language. On a larger level, code-switching can lead to the birth of unhealthy languages which at the later ages pose a threat to the dominant languages. The findings indicate that code-switching should not be encouraged in both spoken and written languages in the classroom despite its significant functions in the classroom instruction. Therefore, there is a negative attitude toward the use of code-switching in language classroom.

Therefore, the outcome of bilingualism in learning a L2 in a language classroom is depicted below.

(i) The research shows that bilingualism has a small but significant impact on language education.

(ii) The L2 should be used extensively in our local setting, because learners have fewer opportunities to speak and apply their L2 outside of the classroom.

(iii) In classes where students share a common L1, bilingualism can be employed as a teaching strategy.

(iv) The research shows that bilingualism in English language classes is both beneficial and effective. However, English should be the primary mode of communication. 
(v) Bilingualism does not detract from students' motivation when utilized appropriately.

\section{Recommendations}

This study's findings include some ideas for improving bilingualism in English classrooms, with a particular focus on results.

- Bilingualism makes it simple to teach more than one language.

- Furthermore, students' motivation isn't lowered as a result of multilingual language instruction.

- The teacher should emphasize on behavior, discipline, and extracurricular activities to keep the students motivated in language learning.

\section{REFERENCES}

Ajmal, M., \& Kumar, T. (2020). Using DIALANG in assessing foreign language proficiency: The interface between learning and assessment. Asian ESP Journal. 16 (2.2), 335 - 362.

Benyo, A. \& Kumar, T. (2020). An analysis of Indian EFL learners' listening comprehension errors. Asian ESP Journal. 16(5.2), 69-85.

Boztepe, E. (2003). Issues in code-switching: competing theories and models. Studies in Applied Linguistics and TESOL, 3(2).

Dendup, P. (2020). Code-Switching in the Classroom: The Perspectives of Bhutanese Teachers. International Journal of Linguistics and Translation Studies, 1(3), 47-57.

Garrett, P. (2010). Attitudes to Language. Cambridge University Press.

Goodman, D. (2006). Language Study in Teacher Education: Exploring the Language in Language Arts. Language Arts, 84(2), 145-156.

Gulzar, M. A. (2010). Code-switching: Awareness about its utility in bilingual classrooms. Bulletin of Education and Research, 32(2), 23-44.

Hakuta, K. (1986). Mirror of language. The debate on bilingualism. Basic Books, Inc., 10 East 53rd Street, New York, NY 10022.
Kumar, T. (2020a). Assessing language need and proficiency of English graduates of Prince Sattam Bin Abdulaziz University for designing pre-placement training and workshops. Asian ErtyreedeefbnvcSP Journal. 16(4), 153-168.

Kumar, T. (2020 b). Impact of motivation and group cohesion in EFL classrooms at Prince Sattam Bin Abdulaziz University, KSA. Asian EFL Journal. 27(4.4), 116-131.

Kumar, T. (2021). 'Desire to learn, learn to shine': Idolizing motivation in enhancing speaking skill among L2 learners. Cypriot Journal of Educational Science. 16(1), 411-422. https://doi.org/10.18844/ cjes.v16i1.5542

Nesamalar, Saratha \& Teh (1995). Code Switching in the Teaching of English as a Second Language to Secondary School Students. Malaysian Journal of ELT Research ISSN: 1511-8002 Vol. 6.

Nesamalar, et al. (1995). Code switching in the teaching of English as a second language to secondary school students. Malaysian Journal of ELT Research. Vol. 6.

Ovando, Collier and Combs (2003). Code Switching in the Teaching of English as a Second Language to Secondary School Students. Malaysian Journal of ELT Research, Vol. 6.

Poplack, S. (2001). Code-switching (linguistic). International encyclopaedia of the social and behavioral sciences, 12 , 2062-2065.

Ryan, E. B., \& Giles, H. (Eds.) (1982). Attitudes towards Language Variation: Social and Applied Contexts (pp. 1-19). London: Edward Arnold.

Shartiely, N. E. (2013). Discourse strategies of lecturers in higher education classroom interaction: a case at the University Dar Es Salaam, Tanzania (Doctoral dissertation, Stellenbosch: Stellenbosch University).

Taha, T. A. (2008). Language alternation in university classrooms. Journal of Instructional Psychology, 35(4), 336346.

Wheeler, R. S., \& Swords, R. (2010). Code-switching lessons: Grammar strategies for linguistically diverse writers: Grades 3-6. Firsthand Heinemann.

Willis (1996). Code Switching in the Teaching of English as a Second Language to Secondary School Students. Malaysian Journal of ELT Research ISSN: 1511-8002, Vol. 6. 